\title{
Amphiphilic silica derivatives associated with oligomeric medium in octamethylcyclotetrasiloxane polymerization
}

\author{
(C) Ruslan S. Davletbaev, ${ }^{1 *}$ Zulfia Z. Faizulina, ${ }^{2+}$ Albina I. Akhmetova, ${ }^{2}$ \\ Samat R. Izmailov, ${ }^{2}$ Daniil A. Demin, ${ }^{2}$ and Ilsia M. Davletbaeva ${ }^{2}$ \\ ${ }^{1}$ Department of Materials Science and Technology of Structural Materials. Kazan National Research \\ Technical University. Karl Marx St., 10. Kazan, 420111. Republic of Tatarstan. Russia. \\ Phone: +7 (843) 231-00-27.E-mail:darus@rambler.ru \\ ${ }^{2}$ Department of Synthetic Rubber Technology. Kazan National Research Technological University. \\ Karl Marx St., 68. Kazan, 420015. Republic of Tatarstan. Russia. \\ Phone:+7 (843) 231-44-55.E-mail:davletbaeva09@mail.ru
}

\begin{abstract}
*Supervising author, ${ }^{+}$Corresponding author
Keywords: amphiphilic branched silica derivatives associated with oligomeric medium, modification, polydimethylsiloxanes, reduced viscosity.
\end{abstract}

\begin{abstract}
The amphiphilic derivatives of silica associated with oligomeric medium have been studied as modifiers of the catalyst for the octamethylcyclotetrasiloxane polymerization of anionic nature. The effect of the modifiers structure on the polymerization time of the obtained polydimethylsiloxanes was investigated. It was found that the modifier, like the initial polyoxyethylene glycol, exhibits the properties of promoters for the catalytic polymerization of octamethylcyclotetrasiloxane by the anionic mechanism. To establish the role of amphiphilic silica derivatives in the occurrence of intermolecular interactions in polydimethylsiloxanes that were obtained with them, the regularities of changes in the reduced viscosity of the obtained modified polydimethylsiloxanes were analyzed. It has been established that the reduced viscosity of polydimethylsiloxanes increases with an increase of the modifier amphiphilicity. This is due to the occurrence of intermolecular interactions because the specific interaction of amphiphilic silica derivatives with polydimethylsiloxane macromolecules. When using amphiphilic derivatives of silica as a modifier of the resulting polydimethylsiloxane to a content of $6 \mathrm{wt} \%$ hydrophobic fragment in their composition, modification of polydimethylsiloxanes does not affect their rheological characteristics. This is due to the presence of polyoxyethylene branches in the composition of the modifier, which creates a cavity for the trapping of $\mathrm{K}^{+}$ions, as in the crown ether, they perform only a catalytic function, which leads to an increase in the rate of the process. However, starting from $10 \%$ wt the content of the hydrophobic component in the composition of the modifier, the reduced viscosity of the obtained polydimethylsiloxane increases due to the occurrence of intermolecular interactions between the modifier and the obtained polydimethylsiloxane. It was noted that polydimethylsiloxane obtained using only polyoxyethylene glycol as a modifier exhibits viscosity characteristics lower than polydimethylsiloxane obtained by the anionic mechanism without using any modifiers.
\end{abstract}

\section{References}

[1] S. Sheiko, B.S. Sumerlin, K. Matyjaszewski. Progress in Polymer Science. 2008. Vol.33. P.759-785.

[2] S.S. Sheiko, S.A. Prokhorova, K.L. Beers, K. Matyjaszewski, I.I. Potemkin, A.R. Khokhlov, M. Möller. Macromolecules. 2001. Vol.34. P.8354-8360.

[3] A.V. Yakimansky, T.K. Meleshko, D.M. Ilgach, M.A. Bauman, T.D. Anan'eva, L.G. Klapshina, S.A. Lermontova, I.V. Balalaeva, W.E. Douglas. Journal of Polymer Science Part A: Polymer Chemistry. 2013. Vol.51. P.4267-4281.

[4] A. Krasova, E. Belyaeva, E. Tarabukina, A. Filippov, T. Meleshko, D. Ilgach, N. Bogorad, A. Yakimansky. Macromolecular Symposia. 2012. Vol.316 (1). P.32-42.

[5] M. Zhang, A.H.E. Müller. Journal of Polymer Science, Part A. Polymer Chemistry. 2005. Vol.43. P.3461-3481.

[6] W. Zhao, P. Fonsny, P. Fitzgerald, G.G. Warr, S. Perrier. Polymer Chemistry. 2013. Vol.4. P.2140-2150.

[7] M. Schappacher, A. Deffieux. Science. 2008. Vol.319. P.1512-1515.

[8] Y. Yan, Y. Shi, W. Zhu, Y. Chen. Polymer. 2013. Vol.54. P.5634-5642. 
AMPHIPHILIC SILICA DERIVATIVES ASSOCIATED WITH OLIGOMERIC MEDIUM...

[9] A. Krasova, E. Belyaeva, E. Tarabukina, A. Filippov, T. Meleshko, D. Ilgach, N. Bogorad, A. Yakimansky. Macromolecular Symposia. 2012. Vol.316(1). P.32-42.

[10] H.-Y. Chang, Y.-L. Lin, Y.-J. Sheng. Macromolecules. 2012. Vol.45. P.4778-4789.

[11] X. Lian, D. Wu, X. Song, H. Zhao. Macromolecules. 2010. Vol.43. P.7434-7445.

[12] R.S. Davletbaev, I.I. Zaripov, Z.Z. Faizulina, I.M. Davletbaeva, D.S. Domrachova, A.M. Gumerov. RSC Advances. 2019. Vol.9. P.21233-21242.

[13] R.S. Davletbaev, O.R. Gumerova, I.M. Davletbaeva. Organic-inorganic gels on the basis of thermodynamically incompatible oligomers. Butlerov Communications. 2013. Vol.35. No.9. P.121-124. ROI: jbc-02/13-35-9-121. 